\title{
(6)
}

\section{QUESTÃO SOCIAL E SERVIÇO SOCIAL NA FORMAÇÃO SÓCIO-HISTÓRICA BRASILEIRA}

\author{
SOCIAL ISSUE AND SOCIAL SERVICE IN BRAZILIAN \\ SOCIAL-HISTORICAL FORMATION
}

\section{Ivone Maria Ferreira da Silva'}

\section{RESUMO}

Este artigo tem como discussão central a emergência e legitimidade da questão social no Brasil. Como resultado das lutas sociais históricas, partimos do reconhecimento de suas raízes, ainda que latentes, como provenientes dos antagonismos da sociedade e da economia colonial-escravista; mesmo compreendendo que a questão social só adquire reconhecimento e publicização tardia nas primeiras décadas do século XX com o desenvolvimento do capitalismo moderno e mediante o processo de industrialização e urbanização da sociedade brasileira. Nesse contexto, constituem-se novas classes fundamentais que, a partir da sua posição antagônica nas relações sociais de produção, dão nova qualidade à questão social e contribuem, dessa forma, para o processo de implantação do Serviço Social no Brasil. Sua vinculação e seu papel no enfrentamento da questão social é outro aspecto aqui discutido.

Palavras-chave: Serviço Social. Questão social. Formação Social Brasileira.

\section{ABSTRACT}

This article discusses the emergency and legitimacy of the social issue in Brazil. As a result of historical social struggles, we start from the recognition of its roots, even though latent, as originating from society antagonisms and from colonial-slavery economy, even understanding

1 Professora do Departamento de Serviço Social da Universidade Federal de Mato Grosso - UFMT. Coordenadora do PPGPS - Mestrado. E-mail: ivone. ferreira@terra.com.br 
that social issue only acquires late recognition and publicization in the first decades of the twentieth century with modern capitalism development and Brazilian society industrialization and urbanization process. In this context, new fundamental classes are constituted, which, from their antagonistic position in social relations of production, provide new quality to social issue and contribute, in this way, to Social Service implementation process in Brazil. Their linkage and role in confronting the social issue is another aspect discussed here.

Keywords: Social Service. Social Issue. Brazilian Social Formation.

Submetido em 28/05/2012

Aceito em 25/09/2012

\section{INTRODUÇÃO}

Ianni (1991) apresenta uma análise histórico-social sobre o processo de formação da questão social no Brasil e afirma, textualmente, que a mesma resulta das diversas crises econômicas próprias do capitalismo brasileiro, via de regra, gerando processos sociais conflitivos no campo e na cidade, desde o período escravista².

Partindo dessa premissa, nossa intenção foi a de demonstrar - com base na historiografia e na sociologia - que a questão social, latente ou explícita, sempre esteve no centro das lutas sociais travadas no interior da sociedade brasileira. Decerto, na maioria das vezes, essas lutas tiveram um caráter elitista, mas sempre buscando a participação das massas: lutas pela terra, migrações internas, servidão e extermínio do indígena, movimento negro, liberdade sindical, protestos sociais dos trabalhadores emergentes da industrialização tardia, etc ${ }^{3}$. Na compreensão desse autor, a representação política da questão social constitui-se pelo descontentamento popular expresso nas lutas por reformas sociais, políticas e econômicas que, em conjunturas históricas diversas, adquire sempre uma nova configuração. Portanto, ela ganha visibilidade no mundo da política.

2 Para lanni (1991), o tema da questão social tem sido objeto de diferentes interpretações teóricas em vários campos das Ciências Sociais. Boa parte dos autores/as que tratam dessa temática reproduz tal afirmação.

3 Ianni já demonstrava esse entendimento para a Sociologia em "A Idéia de Brasil Moderno" (1992), num ensaio dedicado à análise e compreensão acerca da questão social no Brasil. 
Em nossos termos, a questão social traduz-se nas lutas sociais, partidárias ou sindicais que os segmentos ou as classes sociais vêm travando ao longo da formação socioeconômica capitalista do Brasil. Na maioria das vezes, o Estado, a Igreja e o mercado utilizam-se dessas lutas para harmonizar os conflitos e as contradições decorrentes das relações sociais de produção, retardando seu reconhecimento ou legitimidade e dispensando-lhe um tratamento que tem visado apenas garantir os interesses dos estamentos ou das classes dominantes.

Assim, este artigo, entre outros aspectos, pretende mostrar as mudanças ocorridas na sociedade brasileira desde a Colônia. Mudanças que, sem dúvida alguma, contribuíram para as primeiras manifestações da questão social, em especial na turbulência e profusão de movimentos sociais e populares do curto período regencial pelo fim do estatuto colonial. E na sequência, tem-se o golpe que instituiu a $1^{\text {a }}$ República Federativa do Brasil. Com base nessa compreensão, avançamos um pouco mais nosso roteiro de viagem para encontrar nas conjunturas, a partir de 30, - tendo em vista o surgimento do Serviço Social - a expressão "legitimada" da questão social brasileira, ou, no dizer de lamamoto (1993), o momento em que a questão social ganha uma nova qualidade na realidade brasileira.

Passamos, assim, rapidamente, por outras conjunturas importantes: anos de 1940, ainda na vigência do Estado Novo, numa mistura de populismo e ditadura no país e, também, período de institucionalização do Serviço Social como profissão inserida na divisão sociotécnica do trabalho, conforme lamamoto (1993). Um pouco dos anos de 1950 - início do desenvolvimentismo e da consolidação da industrialização brasileira.

Todavia, detivemo-nos mais nas décadas de de 1960 e 1970, caracterizadas como anos difíceis, ou ainda "anos de chumbo", pois representaram mudanças substantivas para o Serviço Social latino-americano. Nessa conjuntura, destacamos o Congresso da Virada em 1979, o qual permitiu ao Serviço Social entrar os anos 1980 trilhando um caminho rico de determinações político-sociais no Brasil, com o processo de redemocratização da sociedade e de "intenção de ruptura" no Serviço Social, como apresenta Paulo 
Netto (1991); momento considerado como de amadurecimento ideopolítico e teórico-metodológico na profissão, apesar dos vários equívocos já bastante analisados.

Finalmente, chegamos aos anos 1990, mostrando que o projeto profissional do Serviço Social colocou a questão social e o processo de trabalho como centralidade da formação em função da revisão curricular determinada pela nova Lei de Diretrizes e Bases da Educação (Lei 9394/1996). Na verdade, tal centralidade é decorrente de mudanças preconizadas desde 1992, no sentido de garantir a eficácia e a efetividade do currículo mínimo vigente.

Desde logo, entendemos que existe uma vinculação entre o Serviço Social e a questão social a qual não se deu por acaso, mas resultante de uma relação histórica. E, nessa perspectiva, é importante trabalhar sua historicidade pela via da formação social brasileira para situarmos em que momento a questão social ganhou materialidade (objetividade) e protagonismo (subjetividade), isto é, expressão e legitimidade no desenvolvimento do processo capitalista de produção, tornando-se, inclusive, base inegável para o surgimento do Serviço Social como profissão. Portanto, a formação histórica da questão social no Brasil constitui-se como o pano de fundo deste artigo.

Vale esclarecer que as considerações aqui condensadas foram extraídas da nossa tese que se fez por um longo percurso de estudo histórico sobre a formação da questão social brasileira e sua vinculação com o Serviço Social. Viagem que começa na sociedade colonial e chega à sociedade em tempos globais, o que nos permite de imediato compreender que a vinculação anteriormente referida não pode ser compreendida fora das condições sócio-históricas da formação social brasileira. Durante o trajeto, isso colocou-nos diante de uma sociedade cravejada de infortúnios.

\section{RAÍZES ESCRAVISTAS DA QUESTÃO SOCIAL NO BRASIL}

No Brasil Colônia, nos deparamos com problemas sociais graves, como o desemprego e a miséria. Conforme afirma Prado Júnior (1970), esses problemas, foram vivenciados por uma população de "vagabundos e desenraizados", utilizados como 
mão-de-obra servil e escrava, numa relação de exploração e dominação de negros e índios. Momento no qual o Estado e a sociedade se faziam presentes de forma muito incipiente: mediante o trabalho de cristianização da Companhia de Jesus e pela aplicação da legislação pombalina: ambas as medidas tendo como objeto a questão indígena.

Sobre esse período, é importante destacar a formação de uma sociedade civil estamental e fechada, em que a população, na sua maioria escrava e negra, era socialmente destituída de suas raízes. Aqui, caberia o uso da categoria exclusão social, na concepção de Martins (2002). Homens e mulheres que tentavam formar uma nova cultura, mesmo que abafada e aniquilada pelo domínio afrouxado do patriarcalismo. Prado Junior (1970) considerou essa sociedade como latente e em transformação, servindo-nos de pista metodológica para afirmarmos a existência das raízes latentes da nossa questão social, ainda na fase colonial de formação da sociedade brasileira.

\section{AS LUTAS SOCIAIS NA MONARQUIA E NA REPÚBLICA VELHA: PRIMEIRAS MANIFESTAÇÕES DA QUESTÃO SOCIAL NO BRASIL}

Seguindo nosso trajeto, identificamos os movimentos sociais ocorridos no Império e na República, destacando a "Independência", em 1822, como processo de emancipação política. Apesar da ausência de uma "consciência de classe", devemos considerar que a independência e os movimentos sociais que se seguiram não se constituíram apenas e, tão somente, pela vontade e para responder às necessidades das elites senhoriais e imperiais, até porque não se tratavam de relações simétricas. Havia, sim, uma subalternidade da massa em relação às elites senhoriais, mas também, e ao mesmo tempo, havia uma dominação da metrópole sobre a colônia, o que relativizava o peso da nossa autonomia política. E é nesse sentido que, a partir de Prado Junior (1969) e Fernandes (1975), conseguimos desmistificar a Independência do Brasil como mero ato heroico emanado da vontade do imperador. Em outros termos: mesmo se tratando de movimentos de caráter elitista, justificavam-se em função da luta contra a dominação colonial. 
Identificamos outras pressões veladas e abafadas referidas ao mundo do trabalho escravo que soavam como o clamor de uma sociedade explorada, dominada e colonizada que, por sua vez, lutava para descolonizar-se. Naturalmente, devido à ausência de uma consciência social e política, esses grupos não conseguiram tirar do cativeiro - ainda depois da abolição formal - grande massa de homens, mulheres e crianças (negros e negras) expropriadas do seu próprio ser, como afirmava lanni (1991).

É inegável, para Fernandes (1975), que a Independência do Brasil, mesmo constituindo-se numa mera revolução pacífica, não significou a simples extinção do estatuto colonial, à medida que, para o autor, teve um sentido socialmente revolucionário. Logo, consideramos sua tese uma novidade, pois atribui um caráter de ruptura à revolução social da Independência, o que nos autoriza questionar os registros históricos de boa parte da historiografia brasileira que ainda hoje nega a dialética dessas transformações. Portanto, considerar a Independência um processo revolucionário não tira dela seu caráter contraditório e conservador, em função de não haver rompimento com estrutura econômica baseada no escravismo.

Outro aspecto a ressaltar relaciona-se ao caráter liberal do movimento abolicionista. Esse caráter, no entanto, não desqualifica sua contribuição na luta pela emancipação dos negros no Brasil, já que denunciou o descumprimento legal de uma série de direitos desconhecido pelos escravos e, dessa forma, foram negados por uma elite oligárquica, monarquista e conservadora.

De passagem pela República de 1889, constatamos, sem dúvida, um avanço no plano político e no plano das ideias no Brasil. Contudo, ao priorizar a modernização administrativa, foram poucas as iniciativas realizadas no que diz respeito à questão social no país. Apenas algumas tentativas isoladas podem ser mencionadas, como por exemplo, as preocupações de Rui Barbosa. Já convencido de que havia uma questão social no Brasil, Rui afastou-se cada vez mais do liberalismo individualista, mas nunca a ponto de assumir-se um socialista, pois temia o conteúdo pernicioso dessa doutrina, o que levaria a nação à anarquia. Defendeu princípios como soberania, nação, cidadania, 
democracia, intervenção estatal, mas dentro dos limites estreitos do liberalismo. Ao Estado, segundo ele, caberia uma justa medida para minimizar os problemas sociais que afligiam a classe operária brasileira, já presentes na $1^{\text {a }}$ República.

Entretanto, o que chamou a atenção nesse ideólogo da causa operária foi sua condição de vida e de trabalho. Essas condições levaram o parlamentar a legislar pela necessidade da construção da casa operária; pela taxação da idade mínima e de salários para menores; higiene e segurança no trabalho; redução da jornada para 8 horas e proibição do trabalho noturno. Já defendia, naquele momento, a licença maternidade de dois meses para o trabalho feminino. O político preocupava-se também com os acidentes, muito comuns nas fábricas, devido às jornadas extensas de trabalho.

Para atuar nos problemas sociais ou no que ele mesmo chamava de questão social, Rui Barbosa pesquisou a fundo a legislação americana e concluiu que havia a necessidade de uma revisão da nossa Constituição em vigor. Por esse motivo, foi o autor da Constituição de 1891.

Tratava-se ainda de uma sociedade que mantinha profundos traços da formação colonial e imperial anteriores, composta de uma massa de miseráveis marginalizados do processo político, que trouxeram, em sua bagagem, o germe da fermentação política. Aos poucos, essa parcela da população mesclava-se com a migração europeia, atraída pelos sonhos da terra prometida. Muitos imigrantes já acumulavam experiência da luta operária europeia, contribuindo como fermento da construção da consciência para si do nascente proletariado brasileiro. Foi desse grau de organização que o Estado e a sociedade passaram a temer, impelindo a tomada de posição frente à questão social, ainda que para enquadrá-la.

\section{O ESTADO NOVO E A LEGITIMIDADE DA QUESTÃO SOCIAL}

Nesse percurso historiográfico, chegamos ao Estado Novo e realizamos o primeiro contato com o Serviço Social durante o governo de Getúlio Vargas. Denominado de autoritário-corporativo, com base em Vieira (1981), essa forma de governo foi palco 
privilegiado nesse cenário histórico no qual vimos reconstruindo a questão social no Brasil. Incrustado de questões herdadas do passado, mas que propunha trazer a modernidade para o país: modernidade da revolução industrial inglesa, da classe operária fabril, do trabalho nas fábricas, das máquinas e equipamentos de produção e de novas formas de investimento econômico que representaram a derrubada da lavoura agrária - base de sustentação da economia até então. Modernidade, também, no plano das ideias com inovação no mundo da cultura e da política. Como as demais mudanças anteriores, essas também foram permeadas por crises, problemas econômicos, políticos e sociais, não obstante, depararam com novos sujeitos e condições objetivas para fazer da questão social o centro de preocupações do Estado e da sociedade.

Tratou-se, do ponto de vista político, de um período em que o pensamento social se formou por diferentes matizes ideopolíticas, do nacionalismo autoritário ao marxismo revolucionário. Nessa profusão de projetos e ideologias, a classe trabalhadora, antes servil, transforma-se em classe operária como protagonista principal do processo de legitimidade da questão social no Brasil. Se existe alguma similaridade, aqui está um dos traços da questão social europeia. De resto, é uma sociedade caracterizada por traços do trabalho escravo, do extermínio da população indígena, do preconceito social e de domínios estamentais/patrimonialistas, conjugados ao domínio autoritário-corporativo.

Uma sociedade em construção, situada num contexto no qual medidas sociais foram tomadas pelo Estado, pela Igreja e, em menor proporção, pelo mercado; medidas visando o tratamento às demandas colocadas pela luta de classes. Foi assim que a questão social, antes latente e obscurecida, ganhou visibilidade e legitimidade no sentido do seu enquadramento. Nessa estratégia de atender para enquadrar a luta dos trabalhadores e suas demandas, o Estado e a Igreja Católica passaram a implantar um conjunto de profissões na área social. Surge, então, o Serviço Social, que, nas suas protoformas, atuava de forma despolitizada com relação à questão social. Não propositadamente, mas de acordo com a visão de mundo renovarista então dominante. 


\section{O SERVIÇO SOCIAL E A BASE CONFESSIONAL- CONSERVADORA DA QUESTÃO SOCIAL}

Quanto à origem do Serviço Social no Brasil, apreendemos a centralidade da Igreja Católica e do Estado nas ações sociais enquanto base confessional-conservadora de atuação das pioneiras e durante o processo de institucionalização da profissão.

As primeiras Escolas de Serviço Social foram criadas em São Paulo e Rio de Janeiro nos anos de 1936 e 1937, em pleno Estado Novo, processo que se deu em meio à nova ordem social, na qual a classe operária assumiu um papel fundamental na luta pelos direitos trabalhistas e por melhores condições de vida, portanto, contra a ausência de um sistema de proteção social no país.

Logo, as primeiras décadas do século XX significaram o início de implementação de medidas de uma legislação social que passou a definir ações de proteção ao trabalho. Porém, o Estado ainda não reconhecia plenamente a questão social, e a Igreja Católica, sempre atrelada a ele, só se preocupava em legitimar sua doutrina social. Nessa fase, a caridade e a filantropia são redimensionadas a partir de uma visão de sociedade propagada pelo pensamento liberal.

Ainda sobre a Igreja Católica - uma das protagonistas na implantação do Serviço Social no Brasil -, sabemos que a instituição religiosa vivia um processo de renovação no qual abandona sua postura passiva e passa a intervir concretamente nos problemas sociais. Para tanto, criou mecanismos importantes como as encíclicas papais: "Rerum Novarum" (1891), de Leão XIII, e "Quadragésimo Anno", (1959), de Pio XII. Esta última, mais próxima da implantação do Serviço Social. Tais instrumentos apostólicos tinham como meta minimizar as graves contradições postas pelo crescimento numérico do proletariado europeu, ainda no século XIX, e foram retomados, na realidade brasileira, pelas pioneiras do Serviço Social, no momento em que se ampliava o quadro de expressões da questão social.

Vale dizer que, até a República Velha, a Igreja se encontrava totalmente imobilizada frente à problemática social, considerando a miséria como resultante da falta de fé e do ócio e, para tanto, defendia o trabalho e a religião como cura para os males 
sociais. Tratava-se, na verdade, de doutrinar e disciplinar a classe operária, a fim de afastar a ameaça do comunismo. Dessa forma, a questão social permaneceu no terreno da ética e da moral, o que Paulo Netto (1992) analisou como moralização da questão social.

Somente a partir da segunda metade da década de 1930, no século XX, que a Igreja Católica enfrentou a questão social pressionada pela nova ordem mundial, o que culminou com a organização do movimento social leigo, no qual estavam incluídas as pioneiras do Serviço Social como agentes de intervenção social. Vivíamos num Brasil composto, de um lado, por uma massa de proletários famintos e miseráveis; de outro, por uma burguesia concentradora e espoliadora da riqueza socialmente produzida. Enfim, um Brasil desigual, com graves expressões da questão social.

O Serviço Social emergiu dessas bases institucionais, monitorado filosoficamente pela doutrina da ação social da Igreja Católica - fundada na filosofia neotomista apontada por Aguiar (1985), propagando um discurso que pretendia criar espaços de participação das massas. Dessa maneira, transformou-se numa instituição de conduta militante contra as injustiças sociais, agregando as nossas pioneiras como parte da estratégia de garantir e avançar a ideia de recristianização da sociedade como forma de enfrentamento da questão social.

Logo, os anos 1940 constituíram-se no contexto de institucionalização do Serviço Social na América Latina - período no qual a classe operária e outros segmentos sociais ganharam densidade nas suas lutas e reivindicações por melhores condições de vida e de trabalho caracterizando, para Carvalho e lamamoto (1993), uma sociedade civil de resistência com ações organizadas e de caráter interventivo. Um momento de grave crise internacional com a iminência da segunda Guerra Mundial.

Na realidade brasileira, vivíamos o Estado Novo que primava pela repressão à luta dos trabalhadores já que os mesmos eram considerados uma ameaça à sociedade. Momento de cooptação e consenso e cuja política de assistência retratava-se por um caráter paternalista e benemerente, baseada numa racionalidade que 
aliava controle social, incremento da produtividade, aumento da taxa de lucro e da exploração dos trabalhadores. Essa conjuntura reverteu-se, até certo ponto, pelo curto período de redemocratização da sociedade brasileira com a eleição de Juscelino Kubitschek (1955-1959), governo considerado como a consolidação da modernidade, pois sustentava-se num ideário econômico e político de defesa do desenvolvimentismo e da democracia, segundo Vieira (1985).

Para Paulo Netto (1991), o Serviço Social surgiu justamente como resultante da complexidade da ordem social burguesa madura e consolidada, atuando de forma individualista e fragmentada, resultado do tratamento residual dado à questão social, em que os conflitos de classe não se traduziam em problemas a serem enfrentados. Não era objeto da ação profissional trabalhar a questão da consciência social, mas apenas disseminar a ideia de um projeto desenvolvimentista; a ideia de educar o cidadão para integrá-lo à promessa de desenvolvimento e progresso.

Foi assim que as pioneiras trataram a questão social: em nome da justiça e da caridade. Nesse período, que atravessou as décadas de 1950 e 1960, o Serviço Social afastou-se da questão social, na defesa de um certo ufanismo pelo bem-estar, buscando explicar de onde e como ele viria, ou se ocorreria por mera vontade do Estado e do capital.

\section{O MOVIMENTO DE RECONCEITUAÇÃO E A POLITIZAÇÃO DA QUESTÃO SOCIAL}

Logo à frente, deparamo-nos com um importante ator: o movimento de reconceituação, tratado aqui de forma breve. Todavia, considerado por muitos autores como um movimento que representou mudanças importantes para profissão. Algumas delas reiterativas, outras de intenção de ruptura, segundo pensamento de Paulo Netto (1991); não obstante todas elas qualificarem, do ponto de vista teórico-metodológico, o Serviço Social latino-americano e brasileiro nas décadas de 70 e 80.

Um movimento que implicou (ou ainda implica) uma disputa de diferentes projetos que visam dar uma direção social para a profissão. Para alguns setores da categoria, a reconceituação já 
se esgotou. Todavia, outros continuam afirmando sua validade na medida em que o Serviço Social não desistiu de participar da construção de um projeto alternativo para a sociedade brasileira e latino-americana.

Esse movimento resultou, na sua origem, da transição do Brasil, que vivia sob um regime ditatorial, na luta pela sua redemocratização. Regime que deixou marcas profundas na sociedade brasileira e do qual a profissão tirou proveito ao questionar profundamente seus parâmetros de inserção política e social. Como contraponto dessa conjuntura, considerada por Paulo Netto (1991) "os anos de chumbo da sociedade brasileira", a reconceituação encontrou fôlego e atualizou-se no processo de transição democrática.

A partir de segunda metade da década de 1980, já se tratava de um Serviço Social renovado, politicamente engajado e teoricamente qualificado. Foi com esse Serviço Social que dialogamos na fase final da nossa tese, fazendo a interlocução com alguns intelectuais dentro e fora do Serviço Social que portam diferentes referências histórico-conceituais na contemporaneidade da questão social.

\section{DA GÊNESE À CENTRALIDADE: O DEBATE CONTEMPORÂNEO DA QUESTÃO SOCIAL}

Nos debates mais recentes sobre questão social, cabe mencionar alguns cientistas sociais com os quais o Serviço Social dialoga e que são portadores de polêmicas significativas. Desde pensá-la como uma expressão utilizada pelo senso comum, passando por aqueles que atribuíram a essa categoria a noção de males e problemas sociais (Igreja e o pensamento social e político conservador); até a compreensão que faz dela o centro do debate no Serviço Social dos anos 90, ao tratá-la como contradição da relação capital x trabalho.

Portanto, a questão social tem sido interpretada como produto da desigualdade social e sinônimo de cidadania, conforme afirma lanni (1991); desagregação e desfiliação (CASTEL, 1997); nova questão social (ROSANVALLON, 1995). A questão social, para além do mundo do trabalho, também envolve as questões 
de gênero, etnia e minorias sociais, segundo Wanderley (1997); além de poder ser vista como um conjunto de problemas econômicos, políticos, sociais e culturais próprias da sociedade capitalista (CERQUEIRA FILHO, 1982), concepção esta, retomada por lamamoto (2003) e Paulo Netto (2004).

Aqui, resumimos nossa incompleta viagem na busca de interpretação da questão social, o que nos permite destacar as mudanças na sua compreensão e formas de enfrentamento, incluindo as formas de atuação do Serviço Social.

No tempo das nossas pioneiras, a questão social já se punha no horizonte da luta de classes capitaneada pela classe operária; entretanto, a Igreja e o Estado intervinham para seu enquadramento. Quanto à intervenção dos (as) assistentes sociais naquele contexto, era de forma absolutamente colada às instituições religiosas e caritativas, o que supõe, do ponto de vista ideopolítico, uma intervenção acrítica. No dizer das próprias pioneiras, tratava-se de uma intervenção norteada por valores morais e cristãos, de conteúdo basicamente eticista, mesmo quando a ação se fazia com mulheres nos centros operários, e já envolvia estudos sobre os direitos trabalhistas. O limite da mudança do status quo era a justiça social. Isso nos leva a supor que as assistentes sociais que abriram o caminho para institucionalização do Serviço Social no Brasil atuavam de forma despolitizada com relação à questão social.

Identificamos que, mesmo na fase mudancista dos anos 1940, 1950 e meados da década de 1960, o Serviço Social não lidava com clareza com as consequências das relações sociais capitalistas. Esse foi um período em que o conceito de bem-estar constituía-se na pedra de toque dos debates em congressos da profissão - quase todos promovidos pelo Centro Brasileiro de Intercâmbio em Serviço Social - CBCISS. Bem-estar, que por sua vez, não se referia às expressões da questão social, mas que fundamentalmente, buscava-se o aperfeiçoamento teórico-metodológico da profissão - via tecnicismo - numa preocupação de responder muito mais as necessidades do modelo de desenvolvimento social em curso. Basta conferirmos os Encontros de Araxá (1967) e Teresópolis (1970). 
Quanto à compreensão de questão social no âmbito do Serviço Social na década de 1990, o debate faz-se de forma heterogênea: como uma variável da luta de classes que só será eliminada com a superação do capitalismo, segundo Netto (2004, 2005); como sinônimo de subalternidade, pobreza e exclusão social e enfrentada na ótica da re-filantropização do social via o apelo à solidariedade. Alteram-se as relações de trabalho, altera-se a questão social e alteram-se seus enfrentamentos, conforme orienta Yazbek (2001). Para Faleiros (2004) e Pereira (2004; 2005) a questão social na atualidade é um problema teórico a ser qualificado.

Para Faleiros (2004), os riscos das diretrizes não darem em nada é iminente, se levarmos em conta a imprecisão categorial da questão social, que sustenta seus desafios atuais para o Serviço Social. Talvez fosse o caso de repensarmos a escolha deste objeto, sustentado no projeto de revisão curricular por uma teoria que não expressa as necessidades da formação em tempos globais. Logo, propõe o paradigma da articulação/regulação que embasa a ação profissional através de redes sociais e institucionais, com o objetivo de fortalecer os sujeitos individuais e coletivos no sentido da transformação da sociedade.

Quanto à Pereira (2004; 2005), o desafio recai sobre a necessidade de deixar claro no projeto de formação o que está se chamando de questão social, num momento de total refluxo da luta de classes, incluindo o cenário internacional, em que não ocorre uma relação política entre os sujeitos coletivos e a estrutura da sociedade. De que questão está se falando? Ela existe? Pergunta a autora. É a questão social que, expressando a contradição capital $x$ trabalho, se agrava na cena contemporânea e coloca novos desafios para o trabalho profissional, para os quais lamamoto (2004) chama a atenção. São todas elas, claramente, posições distintas, porém, em defesa de um projeto alternativo para a sociedade.

\section{CONCLUSÃO}

Para finalizar, diríamos que, ao se analisar o desenvolvimento ou a formação da questão social no Brasil, deve-se evitar negá-la apenas pela ausência de uma participação social e política 
mais consequente - como fazem alguns pensadores - a fim de não alimentarmos e dar mais munição para as classes dominantes, que, historicamente, têm se desobrigado das responsabilidades sobre a nossa questão social, sempre tão mal tratada e mal resolvida. Na nossa perspectiva, negá-la significa o mesmo que dizer que não teve ou não têm mais classes sociais no Brasil e, por consequência, também, não temos luta de classes.

$\mathrm{Na}$ verdade, o que está ocorrendo, por enquanto, é uma crise sem respostas dos sujeitos políticos que sempre estiveram à frente de qualquer processo de mudança social no país. Por isso, consideramos tal polêmica vazia e desmobilizadora, e devemos, nesse sentido, evitar o risco de cairmos numa armadilha ideológica, fazendo coro com uma leitura de base conservadora e reacionária que não valoriza as expressões renovadas da questão social, porque não se quer enfrentá-las. Em outras palavras: negando a questão social, fortalece-se o projeto neoliberal, desobrigando o Estado com relação aos direitos sociais conquistados pelos trabalhadores em mais cem anos de lutas, fragmentando e tornando cada mais focalistas as políticas sociais.

Finalmente, encerramos com uma citação providente, registrada no 18 Brumário:

Ao contrário das revoluções burguesas, as revoluções proletárias [...] não são feitas de ímpetos momentâneos, mas critica-se, interroga-se e interrompe-se constantemente na sua própria marcha, voltam ao que parecia terminado, para começar de novo [...] parece que apenas derrubam seu adversário para que este tire da terra novas forças [...] retrocedem perante a indeterminada enormidade de seus fins, até que se cria uma situação que se torna impossível qualquer retrocesso [...] (MARX, 1984, p. 25).

Marx referia-se às revoluções proletárias do século XIX, O que não nos impede de atualizar suas premissas, pois, em suas palavras, está o essencial para transformar a sociedade vigente: capacidade de luta e paciência histórica. 


\section{REFERÊNCIAS}

AGUIAR, G. A. de. Serviço Social e Filosofia: das origens a Araxá. 3. ed. São Paulo: Cortez, 1985.

CARVALHO, R.; IAMAMOTO, M. V. A Questão Social nas décadas de 20 e 30 e as bases para a Implantação do Serviço Social. In: - Relações Sociais e Serviço Social no Brasil: esboço de uma interpretação histórico-metodológica. 9 ed. São Paulo: Cortez; CELATS (Peru-Lima), 1993. 400p.

CASTEL, R. As armadilhas da exclusão. In: Wanderley, M. B.; Bógus, L.; Yasbek, M. C. (Org.). Desigualdade e Questão Social. São Paulo: EDUC, 1997. p. 15-48.

CENTRO BRASILEIRO DE COOPERAÇÃO E INTERCÃMBIO DE SERVIÇOS SOCIAIS - CBCISS. Teorização do Serviço Social: documentos de Araxá, Teresópolis e Sumaré. 2. ed. Rio de Janeiro: Agir, 1986.

CERQUEIRA FILHO, G. A “questão social” no Brasil: crítica do discurso político dominante. Rio de Janeiro: Civilização Brasileira, 1982.

FALEIROS, V. de P. Aonde nos Levam as Diretrizes Curriculares? Temporalis, Brasília: ABEPSS, ano 1, n. 2. p.163-177, jul/dez. 2000.

FERNANDES, F. A Revolução Burguesa no Brasil: ensaio de Interpretação Sociológica. Rio de Janeiro: Zahar, 1975.

IAMAMOTO, M.V. O Serviço Social na Contemporaneidade: Trabalho e formação profissional. 6. ed. São Paulo: Cortez, 2003.

IAMAMOTO, M. V. A Questão Social no capitalismo. Temporalis, Brasília: ABEPSS; Odisséia, ano 2, n. 3, 2. p. 9-32, jan./jun. 2004.

IANNI, O. A Questão Social. Questão Social. São Paulo em Perspectiva, São Paulo: Fundação SEADE, v. 5, n. 1, p.1-10, jan./ mar. 1991.

. A Idéia de Brasil Moderno. São Paulo: Brasiliense, 1992. 
MARX, K. O 18 Brumário de Louis Bonaparte. Lisboa, Moscovo: Editorial Avante, 1984.

MARX, K. ; ENGELS, F. A ideologia alemã. São Paulo: Hucitec, 1991.

MARTINS, J. de S. A sociedade vista do abismo: novos estudos sobre a exclusão, nobreza e classes sociais. Petrópolis: Vozes, 2002.

NETTO, J. P. Ditadura e Serviço Social: uma análise do Serviço Social no Brasil pós-64. Capítulo II: a renovação do Serviço Social sobre a autocracia Burguesa. São Paulo: Cortez, 1991. p. 115-308.

. As condições histórico-sociais de emergência do Serviço Social. In: Capitalismo Monopolista e Serviço Social. São Paulo: Cortez, 1992. p. 13-77.

. Questão Social. Transcrições das sessões do NEAM: Núcleo de Estudos Marxistas. $1^{\circ}$ semestre de 2000 . Mimeografado.

. Cinco Notas sobre a Questão Social. Revista Temporális, Brasília: ABEPSS; Odisséia, ano 2, n. 3, 2. ed., p. 41-49, jan./jun. 2004.

PAPA LEÃO XIII. Encyclica "Rerum Novarum": sobre a condição dos operários. São Paulo: José Fructuoso da Fonseca \& Cia, 1936.

PAPA PIO XI. A Quadragesimo Anno: sobre a restauração da ordem social. Carta encíclica pelo aniversário de 40 anos da Rerum novarum. Petrópolis, RJ: Vozes, 1959.

PEREIRA, P. A. Questão Social, Serviço Social, e Direitos de Cidadania. Temporalis, Brasília, ABEPESS; Odisséia, ano 2, n. 3, 2. ed., p. 51-61, jan./jun. 2004.

- Comunicação apresentada na aula inaugural do Departamento de Serviço Social na Unb. 2005. Mimeografada.

PRADO JUNIOR, C. Evolução Política e Outros Estudos. 6. ed. São Paulo: Brasiliense, 1969. 
. A Formação do Brasil Contemporâneo: Colônia. 10. ed. São Paulo: Brasiliense, 1970.

ROSANVALLON, P. La Nueva Custión Social. Bueno Aires: Manantial, 1995.

SILVA, I. M. F. da. A Formação Histórica da Questão Social no Brasil e sua Vinculação com o Serviço Social: Uma viagem incompleta, mas repleta de emoções! 2005. Tese (Doutorado em Serviço Social) - Pontifícia Universidade Católica de São Paulo, São Paulo, 2005.

VIEIRA. E. A. Autoritarismo e Corporativismo no Brasil: Oliveira Vianna \& Companhia. 2. ed. São Paulo: Cortez, 1981.

. Estado e Miséria Social no Brasil: Getúlio a Geisel. 2. ed. São Paulo: Cortez, 1985.

YAZBEK, M. C. Pobreza e Exclusão Social: expressões da questão social no Brasil. Temporalis, Brasília: ABEPSS, Grafline; ano 2, n. 3, p. 33-40, jan./jun. 2001.

WANDERLEY, I. E. W. A questão social no contexto da 'globalização': o caso latino americano e caribenho. In: WANDERLEY, Luis Eduardo; BÓGUS, Lúcia; CASTEL, Robert (Org.). Desigualdade social e questão social. São Paulo: EDUC, 1997. p. 49-159. 